\title{
Strategies for maintaining good glycaemic control without recurrent hypoglycaemia
}

\author{
BY I. A. MACDONALD \\ Department of Physiology \& Pharmacology, University of Nottingham Medical School, Queen's Medical \\ Centre, Nottingham NG7 2UH
}

Patients with insulin-dependent diabetes face a major challenge in attempting to maintain normal blood glucose concentrations by effectively balancing their insulin dose, food intake and physical activity. An inadequate amount of insulin relative to food and activity, will lead to elevated blood glucose concentrations and increase the chances of developing the long-term complications of diabetes, whilst an excess of insulin will increase the chances of blood glucose falling to undesirably low levels. The Diabetes Control and Complications Trial (DCCT; The Diabetes Control and Complications Trial Research Group, 1993) showed quite clearly that improving glucose control by intensive insulin therapy reduced the development of diabetic complications such as retinopathy, but that this was at the expense of an increased incidence of severe hypoglycaemia (an occurrence which required the assistance of another person). In other studies, it has become clear that one of the major barriers to patients improving their blood glucose control is the fear of becoming hypoglycaemic (Pramming et al. 1991), and this situation needs to be remedied if a major impact is to be made on the long-term complications of diabetes. The purpose of the present review is to consider the mechanisms by which improved glucose control increases the incidence of hypoglycaemia in patients with insulin-dependent diabetes, and what strategies have been used successfully to prevent this from occurring.

\section{WHAT IS HYPOGLYCAEMIA?}

Hypoglycaemia can be defined biochemically as a blood glucose below the lower limit of normal. However, what is more important is whether this low glucose concentration is associated with physiological disturbances. Until recently, it was assumed that functional disturbances did not occur until blood glucose fell below $3.0 \mathrm{mmol} / 1$ and many clinicians have regarded values below $2.5 \mathrm{mmol} / \mathrm{l}$ as indicating significant hypoglycaemia. However, recent studies have shown impairments of reaction time and significant physiological disturbances at blood glucose values of 3.2-3.5 mmol/1 (Heller et al. 1987). Furthermore, Boyle et al. (1994) have shown significant reductions in brain uptake of glucose and $\mathrm{O}_{2}$ at a plasma glucose of $3.5 \mathrm{mmol} / \mathrm{l}$. To understand how patients may be aware of becoming hypoglycaemic, it is necessary to outline the main physiological and behavioural disturbances which occur as blood glucose falls and the subjective symptoms with which these are associated.

The symptoms of hypoglycaemia are often categorized as being neuroglycopenic or autonomic (Cryer et al. 1989), although it is more appropriate also to have a third category of non-specific symptoms (Hepburn et al. 1991). Neuroglycopenia is literally the shortage of glucose in neural tissue, and in reality most if not all the effects of hypoglycaemia are due to the inadequate supply of glucose to the nervous system. Nevertheless, the neuroglycopenic effects of hypoglycaemia are impaired cognitive function, slowed reactions and reduced ability to concentrate (Heller \& Macdonald, 1996); the subjective symptoms of neuroglycopenia are listed in Table 1 . In addition to these direct effects of 
Table 1. Classification of hypoglycaemic symptoms

(Adapted from Hepburn et al. 1991)

\begin{tabular}{cll}
\hline \hline Autonomic or neurogenic & Neuroglycopenic & Non-specific or both \\
\hline Sweating & Dizziness & Hunger \\
Trembling & Confusion & Blurred vision \\
Warmness & Tiredness & Drowsiness \\
Anxiety & Difficulty speaking & Weakness \\
Nausea & Headache & \\
& Inability to concentrate & \\
\hline
\end{tabular}

Non-diabetic / early diabetes

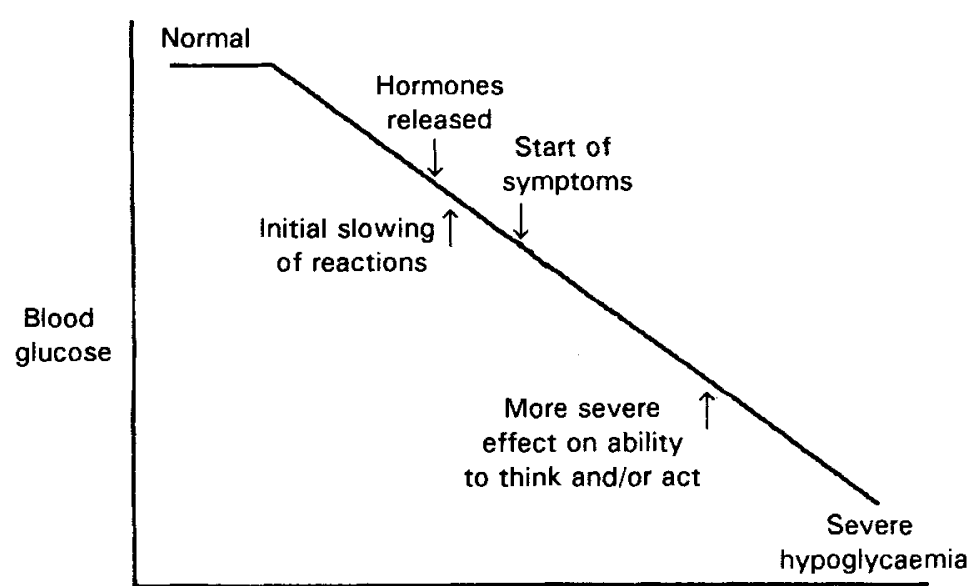

Fig. 1. Hierarchy of physiological changes occurring during the development of hypoglycaemia. (Reproduced from Robinson \& Macdonald, 1993, with permission.)

neuroglycopenia on the central nervous system, hypoglycaemia also leads to activation of the autonomic nervous system. This produces profuse sweating, increased heart rate and pulse pressure, altered peripheral blood flow and marked finger tremor; the subjective autonomic symptoms are listed in Table 1. Many of these peripheral disturbances in hypoglycaemia are mediated by increases in plasma adrenaline, and alteration of these responses can contribute to an individual being unaware of being hypoglycaemic (Heller \& Macdonald, 1991).

The normal hierarchy of changes which occurs during the development of hypoglycaemia is illustrated in Fig. 1. In patients with diabetes of long duration, or with a good degree of blood glucose control, the sequence of these events can change such that subjective symptoms are less marked until glucose falls to much lower concentrations.

\section{WHAT IS HYPOGLYCAEMIA UNAWARENESS?}

This state exists when a patient's blood glucose is in the hypoglycaemic range, but they do not have any subjective symptoms or do not recognize the symptoms as indicating 
hypoglycaemia. A distinction should be made between the situation when blood glucose is low (biochemical hypoglycaemia) but there are no functional disturbances, and the situation where blood glucose is low and brain function is markedly impaired. In the former situation, being unaware of biochemical hypoglycaemia may not be of major importance for the patient, whereas unawareness of the latter is potentially very dangerous.

\section{Biochemical hypoglycaemia without functional impairment}

The clearest example of this situation is seen when alternative substrates are made available for the brain to use in place of glucose. Recent studies by Maran et al. (1994) and Macdonald et al. (1996) have shown that intravenous infusion of lactate reduces subjective symptoms, adrenaline responses and cognitive impairment during hypoglycaemia in both non-diabetic and diabetic subjects. Thus, in this situation the unawareness of hypoglycaemia may be appropriate, as brain function is sustained by the utilization of an alternative metabolic substrate.

Boyle et al. (1994) have shown that maintaining moderate hypoglycaemia for several days in non-diabetic subjects reduces the impairment of brain function produced by a more marked hypoglycaemic challenge. This may be due to an increase in the rate of glucose transport across the blood-brain barrier, again leading to a dissociation of the relationship between blood glucose reduction and disturbed brain function.

\section{Unawareness of hypoglycaemia despite brain dysfunction}

A number of factors can reduce awareness of hypoglycaemia and represent a potentially serious hazard for people with insulin-dependent diabetes. These factors are:

glycaemic control: low glycated haemoglobin $\left(\mathrm{Hb}_{\mathrm{Al}} \mathrm{C}\right)$ increases risk, antecedent hypoglycaemia: reduces awareness of subsequent episode over next few days,

alcohol: prevents recognition of the physiological disturbances during hypoglycaemia.

Glycaemic control. Heller et al. (1987) described one of the first studies in which insulin-dependent diabetic patients with good blood glucose (glycaemic) control had reduced physiological and symptomatic responses to hypoglycaemia compared with patients with poor control, or to non-diabetic subjects. This unawareness of hypoglycaemia (at a blood glucose of $2.5 \mathrm{mmol} / \mathrm{l}$ ) in the patients with good glycaemic control occurred despite a similar impairment of cognitive function (slowing of reaction time, using a choice test) to that seen in the other two groups (Fig. 2).

As mentioned previously, the patients in the DCCT (The Diabetes Control and Complications Trial Research Group, 1993) who undertook intensive insulin therapy to achieve good glycaemic control had a higher incidence of severe hypoglycaemia (sixty-two episodes per 100 patient years) than the patients with poor glycaemic control (nineteen episodes per 100 patient years). No objective assessments of responses to, or awareness of, hypoglycaemia were made in the DCCT, but it is reasonable to conclude that the increased incidence of severe hypoglycaemia was contributed to by the intensively-treated patients having a reduced awareness of developing hypoglycaemia. It is very interesting that there was marked variation in the effect of intensive therapy and good glycaemic control on the incidence of severe hypoglycaemia between the different clinical centres involved in the DCCT. In some centres there was no difference between well-controlled and poorly- 
(a)
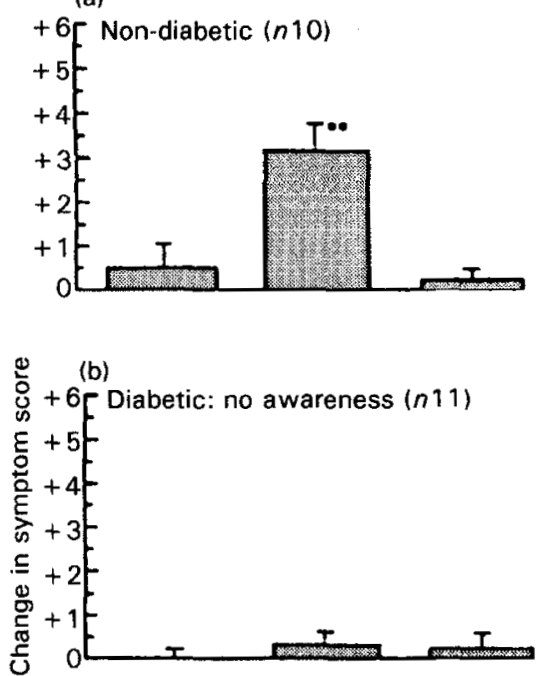

(c)

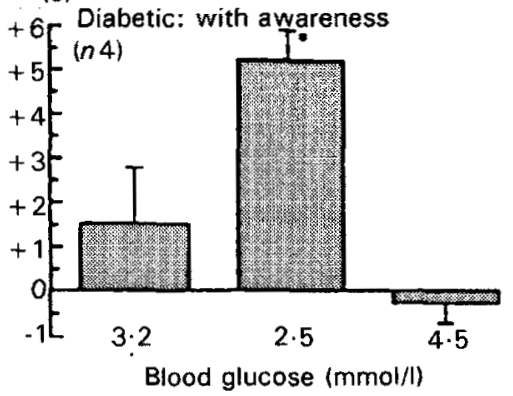

(d)
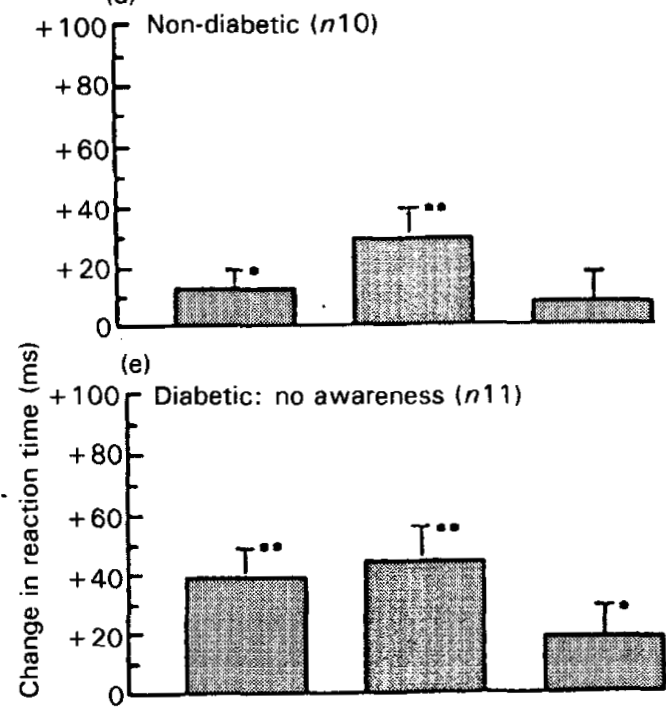

(f)

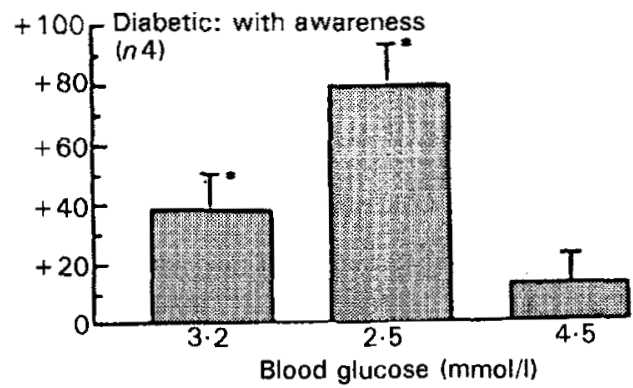

Fig. 2. Change in hypoglycaemic symptoms $(a-c)$ and reaction time $(d-f)$ in non-diabetic subjects (a,d), patients unaware of being hypoglycaemic $(b, e)$ and patients aware of being hypoglycaemic $(c, f)$. Values are the change from the baseline (blood glucose $4.5 \mathrm{mmol} / \mathrm{l}$ ) and are means with their standard errors represented by vertical bars when blood glucose was clamped at $3.2,2.5$ and $4.5 \mathrm{mmol} /$. Mean values were significantly different from baseline values: ${ }^{*} P<0.05, * * P<0.01$. (Reproduced from Heller $e t$ al. 1987 , with permission.)

controlled patients, indicating that good glycaemic control is not irrevocably associated with increased incidence of severe hypoglycaemia (see p. 287).

Antecedent hypoglycaemia. One mechanism which may contribute to the effects of good glycaemic control on the responses to and awareness of hypoglycaemia is related to the effects of frequent, recurrent hypoglycaemia. There is little doubt that if a patient attempts to achieve good glycaemic control without paying extra attention to the situations when blood glucose might fall, (s)he will experience frequent episodes of low blood glucose. Heller \& Cryer (1991) showed in non-diabetic subjects that antecedent hypoglycaemia on the previous day reduced symptomatic and adrenaline responses to hypoglycaemia $18 \mathrm{~h}$ later. Robinson et al. (1995) and George et al. (1995a) extended these observations in non-diabetic subjects to show an effect of antecedent hypoglycaemia for up to $5 \mathrm{~d}$. Similar effects of antecedent hypoglycaemia on responses to hypoglycaemia $18 \mathrm{~h}$ later in patients with insulin-dependent diabetes have been observed by Dagogo-Jack et al. (1993), but a recent study by George et al. (1995b) has suggested this effect may not last as long (only 1-2d) as in non-diabetic subjects. 
Thus, it seems highly probable that if a patient experiences frequent episodes of hypoglycaemia while trying to achieve good glycaemic control, they are likely to be unaware of becoming hypoglycaemic. Such a patient would then be at increased risk of becoming severely hypoglycaemic without having had any warning signs at more moderate levels of hypoglycaemia. This unawareness of mild to moderate hypoglycaemia, increasing the chances of developing severe hypoglycaemia, is a serious threat to the long-term health of patients with insulin-treated diabetes.

Alcohol. Unawareness of being hypoglycaemic can also be caused by any drug which affects brain function in such a way as to impair judgement. The commonest example of this type of effect is the consumption of alcohol. Kerr et al. (1990) showed that alcohol had little effect on the physiological disturbances produced by insulin-induced hypoglycaemia, but that alcohol consumption almost completely prevented both non-diabetic and diabetic subjects from being aware that they were hypoglycaemic (Fig. 3). It is highly likely that this was, at least partly, contributed to by the marked impairment of cognitive function caused by the combination of alcohol and hypoglycaemia.

Thus, anyone responsible for advising people with diabetes on how to avoid hypoglycaemia should warn them of the danger that alcohol can prevent awareness of the normal symptoms of hypoglycaemia. Patients should take extra care to prevent their blood glucose from falling when they consume alcohol.

\section{REVERSIBILITY OF HYPOGLYCAEMIA UNAWARENESS IN PATIENTS WITH INSULIN} DEPENDENT DIABETES

A number of studies have now shown that patients with hypoglycaemia unawareness are able to recover some of their warning symptoms of hypoglycaemia if their diabetic treatment is modified appropriately. For example, Professor Bolli's group in Perugia (Fanelli et al. 1993, 1994) have shown with intensively-treated patients with shorter (7 year; Fanelli et al. 1993) and longer (12 year; Fanelli et al. 1994) duration of diabetes that unawareness of hypoglycaemia can be reversed by altering the treatment strategy. Moreover, Fanelli et al. (1994) reported that the reversal of the previously well-established hypoglycaemia unawareness lasted for at least 1 year. This improvement of awareness of hypoglycaemia was achieved by initiating an intensive-treatment programme designed to avoid hypoglycaemia during everyday life. This approach is described in more detail later (see p. 287), but it is noteworthy that the modified treatment regimen led to a slight worsening of glycaemic control, with the level of $\mathrm{Hb}_{\mathrm{A} 1} \mathrm{C}$ rising from $5.8 \%$ (when the patients had hypoglycaemia unawareness) to $6.9 \%$ after 1 year. The upper limit of the nondiabetic range for $\mathrm{Hb}_{\mathrm{A} 1} \mathrm{C}$ was said to be $5.5 \%$, and Fanelli et al. (1994) commented that attempts by patients to achieve normal $\mathrm{Hb}_{\mathrm{A} 1} \mathrm{C}$ values should be discouraged. Such an unrealistic goal will undoubtedly produce frequent episodes of mild to moderate hypoglycaemia which are then likely to lead to hypoglycaemia unawareness. Thus, any intensive treatment regimen for patients with insulin-dependent diabetes should have a target $\mathrm{Hb}_{\mathrm{A} 1} \mathrm{C}$ value of approximately $7.0 \%$, which was the mean value achieved by the well-controlled group in the DCCT (The Diabetes Control and Complications Trial Research Group, 1993).

A similar improvement in awareness of hypoglycaemia was demonstrated by Cranston et al. (1994), who studied patients with a long duration (11-32 years) of diabetes and who had a history of hypoglycaemia unawareness. Many clinicians would expect that patients with such a long duration of diabetes would not be able to recover their warnings of hypoglycaemia, but Cranston et al. (1994) showed that altering their therapy to avoid 


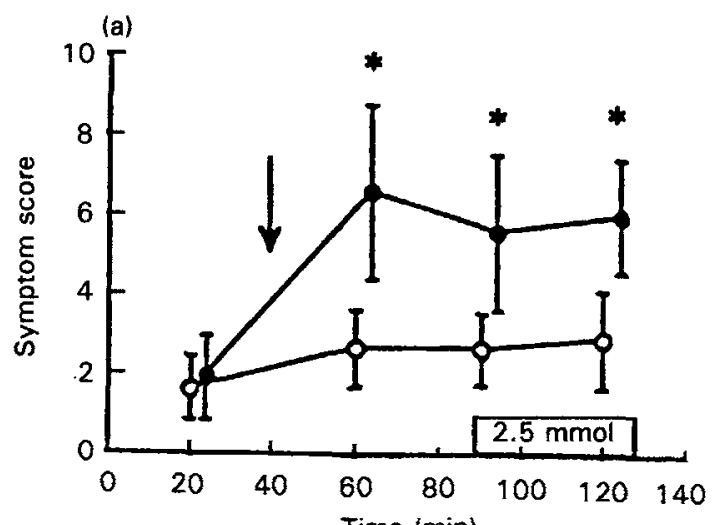

(b)

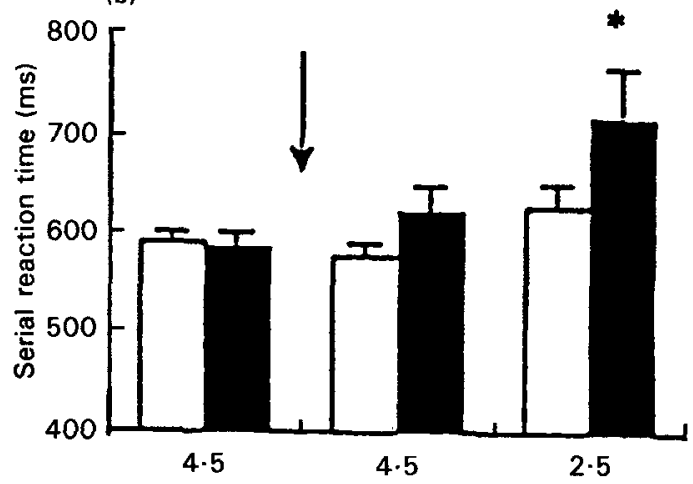

(c)

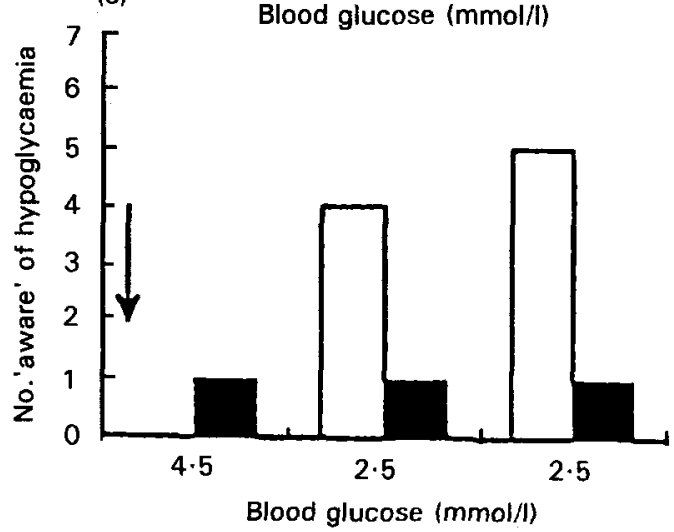

Fig. 3. Combined effects of alcohol ingestion and hypoglycaemia on (a) symptoms of hypoglycaemia, (b) reaction time and (c) the no. of patients aware of being hypoglycaemic. Values are means with their standard errors represented by vertical bars. $\downarrow$. Time of ingestion of alcohol or fruit juice. (a), Blood glucose was $2.5 \mathrm{mmol} /$ between 90 and $130 \mathrm{~min}$; $(b, c)$, blood glucose values indicate the level of glycaemia at each measurement point. $(O, \mathbf{D})$, Alcohol day; $(O, \square)$, control day. Mean values were significantly different from control values: $* P<0 \cdot 05$. (Reproduced from Kerr et al. 1990, with permission.) 
hypoglycaemia for a minimum of 3 weeks led to improved awareness of, and adrenaline response to, experimental hypoglycaemia. Moreover, whilst half the subjects studied by Cranston et al. (1994) had good glycaemic control, the remaining patients did not. Instead, the remainder had rather poor glycaemic control and were more representative of the 'brittle' type of diabetic patient who have regular swings between marked hypoglycaemia and marked hyperglycaemia.

It is reassuring that in the studies undertaken so far, it seems to be possible to reverse hypoglycaemia unawareness. There will undoubtedly be some patients in whom this is not possible, but this should not discourage patients and their diabetes specialist care advisers from trying. However, it is also important that the principles applied to reverse this established unawareness of hypoglycaemia are also introduced into the routine treatment of newly-diagnosed patients and of those who at present are aware of being hypoglycaemic. This would enable good glycaemic control to be achieved without increasing the incidence of hypoglycaemia and, thus, reduce the chances of both long-term complications of diabetes and of experiencing frequent episodes of severe hypoglycaemia.

\section{AVOIDANCE OF HYPOGLYCAEMIA WHILE ACHIEVING GOOD GLYCAEMIC CONTROL}

The strategies used by Fanelli et al. $(1993,1994)$ and Cranston et al. (1994) (see p. 285) to reverse unawareness of hypoglycaemia also provide the foundation for initiating intensive insulin therapy in all patients whilst avoiding recurrent hypoglycaemia. The key features are to educate patients effectively in relation to insulin action and appropriate dosage, nutrition and physical activity, and to set realistic and appropriate targets for the degree of glycaemic control which should be sought. These principles are clear and simple, and many (if not all) diabetic clinics would claim that they operate to a similar plan. However, in the majority of clinics, the patients who have good glycaemic control will also have frequent episodes of hypoglycaemia and tend to be unaware of them. Thus, it is worth considering the detailed features of the education programmes which have succeeded in achieving good glycaemic control without excessive hypoglycaemia.

\section{Glucose targets}

A key component of the education programmes is the frequent monitoring of blood glucose by capillary sampling and reflectance meter measurement, at least in the early stages of the new treatment strategy. In fact, most patients are also encouraged to test their blood glucose before every meal, and to perform more-frequent testing at least once weekly. Most of the programmes suggest that pre-meal glucose values should be approximately $7 \mathrm{mmol} / \mathrm{l}$, and that the $\mathrm{Hb}_{\mathrm{A} 1} \mathrm{C}$ targets should be $6.5-7.0 \%$ (when the upper limit of normal is $5.5 \%$ ).

\section{Therapeutic strategies: Perugia}

The key features of the intensive therapy which is used by Professor Bolli's group (Fanelli et al. 1993, 1994) are to have three meals per day, with no snacks between, with an injection of short-acting soluble insulin before each meal, and of longer-acting insulin at bedtime. In addition, patients are encouraged to measure their blood glucose before each meal, and modify their insulin dose according to the glucose value. In the early stages of the treatment, the patients are encouraged to contact their physician regularly by telephone (up to four times daily) in order to discuss how their treatment should proceed. 
Whilst this approach may sound rather demanding, at least initially, it is clearly effective and it is likely to become less demanding as the patients become more familiar with the principles. An example of the effectiveness of this programme is presented by Pampanelli et al. (1996). They recruited 112 patients at diagnosis of insulin-dependent diabetes, and studied them for a mean of 7.8 years. These patients had a mean $\mathrm{Hb}_{\mathrm{A} 1} \mathrm{C}$ of $7.1 \%$ and an incidence of severe hypoglycaemia of one event per 100 patient years. This contrasts with the intensively-treated group in the DCCT (The Diabetes Control and Complications Trial Research Group, 1993) who had a similar degree of glycaemic control, but an incidence of severe hypoglycaemia of sixty-two events per 100 patient years. Moreover, in the study by Pampanelli et al. (1996) the subgroup of patients with the best glycaemic control $\left(\mathrm{Hb}_{\mathrm{A} 1} \mathrm{C}\right.$ less than $\left.5.5 \%\right)$ had an increased incidence of biochemical hypoglycaemia during their routine testing, and had decreased responses to and awareness of experimental hypoglycaemia. By contrast, the patients with a $\mathrm{Hb}_{\mathrm{Al}} \mathrm{C}$ above $6.1 \%$ had normal hormonal responses to and awareness of experimental hypoglycaemia.

\section{Therapeutic strategies: Düsseldorf}

The other group with extensive experience of successfully combining good glycaemic control of insulin-dependent diabetes with reduced incidence of severe hypoglycaemia is based in Düsseldorf and led by Dr Mühlhauser and Professor Berger. Their original programme involved an intensive $5 \mathrm{~d}$ in-patient education programme with subsequent follow-up and was based on the programme initially developed by J.-P. Assal in the mid 1970s (Assal et al. 1983, 1985). This programme has been used in Düsseldorf since 1978, initially in the specialist Department of Metabolic Diseases and Nutrition. However, the approach has been effectively introduced into a general hospital setting (Jörgens et al. 1993), and more recently into an outpatient setting (Pieber et al. 1995). The goal of the programme is to educate the patients in such a way that they can adopt a very flexible

Table 2. Diabetes Education Programme: an outline of the topics covered in the 'Düsseldorf' education programme

(Reproduced from information provided by Dr Ingrid Mühlhauser, with her permission)

\begin{tabular}{|c|c|c|c|c|}
\hline \multicolumn{5}{|c|}{ Diabetes education schedule } \\
\hline Monday & Tuesday & Wednesday & Thursday & Friday \\
\hline What is diabetes? & $\begin{array}{l}\text { Nutrition } \\
\text { Insulin action }\end{array}$ & $\begin{array}{l}\text { Blood gluco } \\
\text { Insulin adaptation } \\
\text { Rounds with } \\
\text { the Professor }\end{array}$ & $\begin{array}{l}\text { testing } \\
\text { Nutrition } \\
\text { Exercise }\end{array}$ & $\begin{array}{l}\text { Nutrition } \\
\text { Contraception } \\
\text { and/or pregnancy } \\
\text { Role play }\end{array}$ \\
\hline Self monitoring & $\begin{array}{l}\text { Insulin strategies } \\
\text { and injection } \\
\text { technique }\end{array}$ & $\begin{array}{l}\text { Visit to the } \\
\text { supermarket }\end{array}$ & $\begin{array}{l}\text { Exercise and } \\
\text { diabetes }\end{array}$ & $\begin{array}{l}\text { Long-term } \\
\text { complications }\end{array}$ \\
\hline Individual therapeutic goals & Hypoglycaemia & $\begin{array}{l}\text { Coping with diabetes: } \\
\text { discussion and } \\
\text { strategies }\end{array}$ & $\begin{array}{l}\text { Social aspects } \\
\text { Insulin dosage } \\
\text { adaptations: } \\
\text { illness }\end{array}$ & Quiz \\
\hline
\end{tabular}


lifestyle by modifying their insulin dose to cope with regular variations in diet and physical activity. An illustration of the topics covered during the education programme is shown in Table 2. A follow-up assessment of 636 patients who had undergone this teaching programme 6 years earlier revealed a reasonable degree of glycaemic control (mean $\mathrm{Hb}_{\mathrm{A} 1} \mathrm{C}$ $7.9 \%)$, which was better than before they entered the teaching programme $(8.3 \%)$, and a reduced incidence of severe hypoglycaemia (seventeen $v$. twenty-eight events per 100 patient years). The liberalization of the diet was illustrated by the fact that only $11 \%$ of patients followed a strict meal plan over the 6 years after the intensive education programme, and $85 \%$ of them regularly consumed sugar or sugar-containing foods (Mühlhauser et al. 1995). Whilst the degree of glycaemic control is not as good as achieved by Professor Bolli's group (Fanelli et al. 1993, 1994), it is likely to impart a substantial benefit with regard to reducing the risk of developing long-term complications of diabetes. In addition, the liberal basis of the treatment programme is likely to be more attractive to the majority of patients, increasing the chances of compliance. Moreover, the demonstration that this approach is effective outside the specialist diabetes centre is of great interest.

The approach taken by Cranston et al. (1994) to avoid hypoglycaemia in those patients with hypoglycaemia unawareness is similar to those described previously, but has not yet been applied to larger groups. It is of interest that the main difference from the principles of the Perugia programme (Fanelli et al. 1993, 1994) was that patients of Cranston et al. (1994) were advised to eat regular snacks throughout the day and before bed. Particular attention was paid to the times of greatest risk of hypoglycaemia, i.e. in relation to increased physical activity and during the night time.

\section{CONCLUSIONS}

It is interesting, and somewhat distressing, that although 75 years have passed since the discovery of insulin, its use in the treatment of patients with diabetes still produces problems with hypoglycaemia. A substantial number of patients run the risk of developing severe hypoglycaemia, with the possibility of becoming unconscious, without previous warnings. However, it is now clear that this problem can be addressed by improved education of the patients (and also probably some of their advisers) about their diabetes. The target for the 21 st century should be to ensure that until diabetes can be cured, and/or prevented, steps are taken to ensure that all patients have access to an effective education programme which will enable them to reduce the risks of developing severe hypoglycaemia whilst achieving good glycaemic control.

I am most grateful to Dr Ingrid Mühlhauser, Professor Geremia Bolli and Dr Iain Cranston for providing me with the details of their education programmes and for allowing me to describe them in this review. I am also very grateful to Ms Kirsty Hitt for help in preparing this manuscript.

\section{REFERENCES}

Assal, J. P., Berger, M., Gay, N. \& Canivet, J. (editors) (1983). Diabetes education: how to improve patient education. In International Congress Series no. 624. Amsterdam, Oxford and Princeton: Exerpta Medica.

Assal, J. P., Mühlhauser, 1., Pernet, A. Gfeller, R., Jörgens, V. \&. Berger, M. (1985). Patient education as the basis for diabetes care in clinical practice and research. Diabetologia 28, 602-613.

Boyle, P. J., Nagy, R. J., O'Connor, A. M., Kempers, S. F., Yeo, R. A. \& Qualls, C. (1994). Adaptation in brain glucose uptake following recurrent hypoglycemia. Proceedings of the National Academy of Sciences, USA 91 , 9352-9356. 
Cranston, I., Lomas, J., Maran, A., Macdonald, I. \& Amiel, S. A. (1994). Restoration of hypoglycaemia unawareness in patients with long-duration insulin-dependent diabetes. Lancet 344, 283-287.

Cryer, P. E., Binder, C., Bolli, G. B., Cherrington, A. D., Gale, E. A. M., Gerich, J. E. \& Sherwin, R. S. (1989). Hypoglycemia in IDDM. Diabetes 38, 1193-1199.

Dagogo-Jack, S. E., Craft, S. \& Cryer, P. E. (1993). Hypoglycemia-associated autonomic failure in insulindependent diabetes mellitus. Journal of Clinical Investigation 91, 819-828.

Fanelli, C. E., Epifano, L., Rambotti, A. M., Pampanelli, S., Di Vincenzo, A., Modarelli, F., Lepore, M., Annibale, B., Ciofetta, M., Bottini, P., Porcellati, F., Scionti, L., Santeusanio, F., Brunetti, P. \& Bolli, G. B. (1993). Meticulous prevention of hypoglycemia normalises the glycaemic thresholds and magnitude of most of neuroendocrine responses to, symptoms of, and cognitive function during hypoglycemia in intensively treated patients with short-term IDDM. Diabetes 42, 1683-1689.

Fanelli, C., Pampanelli, S., Epifano, L., Rambotti, A. M., Di Vincenzo, A., Modarelli, F., Ciofetta, M., Lepore, M., Annibale, B., Torlone, E., Perriello, G., De Feo, P., Santeusanio, F., Brunetti, P. \& Bolli, G. B. (1994). Long-term recovery from unawareness, deficient counterregulation and lack of cognitive dysfunction during hypoglycaemia, following institution of rational, intensive insulin therapy in IDDM. Diabetologia 37, 12651276.

George, E., Harris, N., Bedford, C., Macdonald, I. A., Hardisty, C. A. \& Heller, S. R. (1995a). Prolonged but partial impairment of the hypoglycaemic physiological response following short-term hypoglycaemia in normal subjects. Diabetologia 38, 1183-1190.

George, E., Marques, J., Harris, N., Hardisty, C. A. \& Heller, S. R. (1995b). Physiological responses to hypoglycaemia are not reduced 2 days after antecedent hypoglycaemia in IDDM. Diabetologia 38, Suppl. 1, A18.

Heller, S. R. \& Cryer, P. E. (1991). Reduced neuroendocrine and symptomatic responses to subsequent hypoglycemia after 1 episode of hypoglycemia in non-diabetic humans. Diabetes 40, 223-226.

Heller, S. R. \& Macdonald, I. A. (1991). Physiological disturbances in hypoglycaemia: effect of subjective awareness. Clinical Science 81, 1-9.

Heller, S. R. \& Macdonald, I. A. (1996). The measurement of cognitive function during acute hypoglycaemia: Experimental limitations and their effect on the study of hypoglycaemia unawareness. Diabetic Medicine 13, 607-615.

Heller, S. R., Macdonald, I. A., Herbert, M. \& Tattersall, R. B. (1987). Influence of the sympathetic nervous system on hypoglycaemia warning symptoms. Lancet ii, 359-363.

Hepburn, D. A., Deary, I. J., Frier, B. M., Patrick, A. W., Quinn, J. D. \& Fisher, B. M. (1991). Symptoms of acute insulin induced hypoglycemia in humans with and without IDDM: Factor-analysis approach. Diabetes Care 14, 949-957.

Jörgens, V., Grüsser, M., Bott, U., Mühlhauser, I. \& Berger, M. (1993). Effective and safe translation of intensified insulin therapy to general internal medicine departments. Diabetologia 36, 99-105.

Kerr, D., Macdonald, I. A., Heller, S. R. \& Tattersall, R. B. (1990). Alcohol causes hypoglycaemia unawareness in healthy volunteers and patients with type 1 (insulin dependent) diabetes. Diabetologia 33, 216-221.

Macdonald, I. A., King, P., Parkin, H., Kong, M.-F., Barber, C. \& Tattersall, R. B. (1996). Intravenous lactate protects cerebral function during hypoglycaemia. Diabetologia 39, Suppl. 1, A57.

Maran, A., Cranston, I., Lomas, J., Macdonald, I. A. \& Amiel, S. A. (1994). Protection by lactate of cerebral function during hypoglycaemia. Lancet 343, 16-20.

Mühlhauser, I., Bott, U., Overmann, H., Wagener, W., Bender, R., Jörgens, V. \& Berger, M. (1995). Liberalised diet in patients with type 1 diabetes. Joumal of Internal Medicine 237, 591-597.

Pampanelli, S., Fanelli, C., Lalli, C., Ciofetta, M., Del Sindaco, P., Lepore, M., Modarelli, F., Rambotti, A. M., Epifano, L., Di Vincenzo, A., Bartocci, L., Annibale, B., Brunetti, P. \& Bolli, G. B. (1996). Long-term intensive insulin therapy in IDDM: effects of $\mathrm{HBA}_{1 \mathrm{C}}$, risk for severe and mild hypoglycaemia, status of counterregulation and awareness of hypoglycaemia. Diabetologia 39, 677-686.

Pieber, T. R., Brunner, G. A., Schnedl, W. J., Schattenberg, S., Kaufmann, P. \& Grejs, G. J. (1995). Evaluation of a structured outpatient group education program for intensive insulin therapy. Diabetes Care 18, 625-630.

Pramming, S., Thorsteinsson, B., Bendtson, I. \& Binder, C. (1991). Symptomatic hypoglycaemia in 411 type 1 diabetic patients. Diabetic Medicine 8, 217-222.

Robinson, A. M. \& Macdonald, I. A. (1993). Pathophysiology of hypoglycaemia. In The Diabetes Annual 7, pp. 303-316 [S. M. Marshall, P. D. Home, K. G. M. M. Alberti and L. P. Krall, editors]. Amsterdam: Elsevier.

Robinson, A. M., Parkin, H. M., Macdonald, I. A. \& Tattersall, R. B. (1995). Antecedent hypoglycaemia in nondiabetic subjects reduces the adrenaline response for 6 days but does not affect the catecholamine response to other stimuli. Clinical Science 89, 359-366.

The Diabetes Control and Complications Trial Research Group (1993). The effects of intensive treatment of diabetes on the development and progression of long-term complications in insulin-dependent diabetes mellitus. New England Journal of Medicine 329, 977-986. 